\title{
Eibar y la industria armera: evidencias de un distrito industrial
}

\section{Eibar and the gun making industry: evidence of an industrial district}

\author{
IGOR GOÑI MENDIZÁBAL \\ Universidad del País Vasco
}

\begin{abstract}
RESUMEN
ABSTRACT

La industria armera vasca experimentó su máximo crecimiento a finales del siglo XIX y comienzos del $\mathrm{xx}$ gracias, principalmente, al crecimiento de las exportaciones de armas cortas y revólveres que llegaron a suponer en torno al 90 por 100 del total de sus ventas. Esta industria se encontraba concentrada en torno a

la localidad de Eibar que, junto a otras poblaciones guipuzcoanas y vizcaínas, conformaban la denominada "Zona armera". La competitividad internacional de la industria armera de Eibar respondía en gran medida a la flexibilidad y adaptabilidad otorgadas por su estructura de distrito industrial marshalliano

clásico. En Eibar coinciden muchas de las características propuestas por la literatura sobre distritos industriales destacando, entre otras, la especialización en un producto relativamente

homogéneo como las armas de fuego, el predominio de las PYME en su estructura productiva y las relaciones de subcontratación entre ellas, la existencia de reglas internas e instituciones que velan por el cumplimiento de las mismas, así como la creación, gracias a la cooperación entre empresas, de instituciones para el fomento del desarrollo de la industria

The Basque Gunmaking industry experienced its most important growth during the last decades of the $19^{\text {th }}$ century and first years of the $20^{\text {th }}$. This growth was due to the increasing exports of revolvers and pistols which made up almost 90 per cent of total sales. This industry was concentrated around the town of Eibar which, together with other villages of Guipuzcoa and Biscay, constituted the "Gunmaking Zone". The international competitiveness achieved by this industry was mainly a consequence of the flexibility and adaptability given by its Marshallian industrial district structure since Eibar fulfilled most of the characteristics cited by specialized literature, e.g., specialization, in this case in firearms, a relatively homogeneous product; predominance of SME in its production structure and subcontracting relationships among them; existence of internal rules and institutions that protect them; and, due to cooperation between companies, creation of institutions to improve the development of the district's characteristic industry.
\end{abstract} característica del distrito.

PALABRAS CLAVE: Armas, Industria armera, Distrito Industrial, País Vasco

Código JEL: N63, N64

KEY WORDS: Guns, Gunmaking industry, Industrial District, Basque Country

JEL Codes: N63, N64 


\section{Introducción ${ }^{1}$}

finales de la década de los 70 del siglo pasado Giacomo Becattini trató de
dar una explicación al dinamismo que las pequeñas y medianas empresas los 60 y $70^{2}$. Esta realidad contradecía en cierto modo la teoría económica imperante por aquel entonces que daba por supuesta una correlación positiva entre la competitividad de las empresas y el tamaño de las mismas. El esfuerzo de Becattini por dar una explicación a ese hecho le llevó a rescatar y desarrollar el concepto de distrito industrial que Alfred Marshall había esbozado en sus escritos de finales del siglo XIX y principios del XX.

Algunos autores han citado a Eibar y su industria armera como un ejemplo clásico de distrito industrial marshalliano, aunque, quizá por considerarse evidente, no ha sido efectuado aún, desde esta perspectiva, un estudio en profundidad sobre el caso de esta localidad guipuzcoana ${ }^{3}$. El objetivo del presente artículo es llevar a cabo un primer acercamiento al caso de la industria armera de Eibar desde el enfoque de distrito, mostrando varias evidencias que demuestran la veracidad de cuanto hasta ahora se presuponía. Este análisis debería, quizá, abarcar un período mucho más amplio que el que va a ser tratado en este trabajo; pero, tratándose de una primera aproximación a este enfoque, consideramos más adecuado centrarnos en el período de mayor esplendor de la industria armera, el comprendido entre 1876 y 1936, pues fue entonces cuando, sin duda, mayor intensidad mostraron los mecanismos asociados a los distritos industriales.

\section{El distrito industrial marshalliano}

En los primeros escritos de Alfred Marshall aparecía de forma embrionaria el concepto de distrito industrial destacando que algunas de las ventajas asociadas a la división del trabajo no tenían por qué obtenerse únicamente en fábricas muy gran-

[Fecha de recepción del original, 27 de octubre de 2008. Versión definitiva, 18 de marzo de 2009].

1 Una primera versión de este artículo se presentó como comunicación en la sesión plenaria "Empresas y distritos industriales en el mercado mundial" del IX Congreso Internacional de la Asociación Española de Historia Económica celebrado en Murcia en septiembre de 2008. Es mi obligación agradecer los comentarios que los coordinadores y participantes en la misma realizaron sobre mi trabajo tanto en el Congreso como en la sesión preparatoria celebrada en Alicante en junio de aquel mismo año. También he de agradecer las recomendaciones de los evaluadores que, sin duda, han permitido mejorar el resultado final de este trabajo.

Becattini (1979).

Valdaliso y López (2000), p. 325. 
des, sino que éstas podían conseguirse mediante la asignación de las distintas fases de la producción a pequeñas fábricas independientes ${ }^{4}$. En trabajos posteriores también constató la tendencia de ciertas industrias hacia la concentración geográfica con el objeto de obtener economías asociadas a la proximidad. Así, en estos distritos, se crea una especie de "ambiente industrial" en el que los conocimientos se adquieren de forma casi natural y los inventos e innovaciones, al extenderse y ser conocidos fácilmente por el resto de los miembros del distrito, son evaluados y perfeccionados para beneficio del conjunto del mismo ${ }^{5}$. En resumen, para Marshall existirían dos maneras de conseguir rendimientos crecientes en la industria. Una sería la concentración de la producción en grandes empresas integradas verticalmente y, la otra, la concentración territorial de un elevado número de pequeñas empresas que cooperan y compiten entre sí. En este último caso, si la producción puede ser segmentada en varias fases y existe una masa crítica de empresas, se pueden obtener rendimientos crecientes que no están relacionados con el tamaño de la empresa sino con el territorio en el que ésta está localizada. Así, se producirían crecimientos de la productividad debido a la existencia de economías externas a la empresa pero internas al área en la que ésta realiza su actividad, como la existencia de un mercado de trabajo local que reduce los costes de transacción para las empresas o la cooperación entre las fuerzas sociales y económicas que se materializa, en ocasiones, en relaciones de amistad entre patronos y empleados ${ }^{6}$.

Las afirmaciones de Marshall sobre los distritos industriales no se adaptaban bien a la teoría económica clásica por lo que fueron marginadas de la corriente principal del pensamiento económico. Pero a finales de la década de 1970 Giacomo Becattini recuperó el concepto de distrito como instrumento de análisis de los procesos industriales. Basándose en su estudio sobre la industria textil de la localidad toscana de Prato, observó que en la zona central de la Italia de los años 50-60 se estaba produciendo un proceso de industrialización fuera de la norma ${ }^{7}$. Allí, contra todo pronóstico, destacaba el protagonismo de las pequeñas y medianas empresas especializadas en actividades manufactureras ligeras y con un elevado grado de concentración geográfica. Estos distritos disponían de una elevada capacidad competitiva, tanto en el ámbito nacional como internacional, con niveles de calidad simi-

"We shall find that some of the advantages of division of labour can be obtained only in very large factories, but many of them, more than at first sight appears, can be secured by small factories and workshops, provided there are a very great number of them in the same trade." Marshall A. y Marshall M.P. (1879), p. 52.

$5 \quad$ "Where large masses of people are working at the same kind of trade, they educate one another. The skill and the taste required for their work are in the air, and children breathe them as they grow up." Marshall A. y Marshall M.P. (1879), p. 53.

Marshall (1954), p. 227.

Becattini (1979). 
lares a los de empresas de mayor tamaño ${ }^{8}$. Tras el primer trabajo de Becattini otros autores desarrollaron este enfoque y aportaron nuevos estudios de caso no sólo para Italia sino también para otros países.

Piore y Sabel, por su parte, quisieron ver en el comportamiento relativamente favorable de algunos distritos industriales durante la crisis de los 80 una manifestación de la ruptura con el paradigma de la gran empresa fordista9 ${ }^{9}$ Según esta visión, integrada en el concepto de "especialización flexible", el capitalismo industrial estaba entrando en una nueva fase en la que las pequeñas y medianas empresas, empleando trabajadores especializados y maquinaria versátil, podían competir con las grandes empresas al menos en productos que no se prestasen a largas series de producción ${ }^{10}$. Otro concepto que ha tenido éxito en paralelo al de distrito industrial ha sido el de cluster que ha participado, igualmente, en la erosión de la hegemonía del concepto de sector industrial ${ }^{11}$ y que, al obviar los aspectos socio-culturales del planteamiento de Becattini, incorpora una variedad más amplia de sistemas productivos locales ${ }^{12}$.

Según Becattini, un distrito industrial se puede definir como una entidad socioterritorial que se caracteriza por la presencia activa tanto de una comunidad de personas como de un conjunto de empresas en una zona natural e históricamente determinada ${ }^{13}$. La interacción entre ambos ámbitos está reglada por un sistema de valores e ideas relativamente homogéneo que se difunde y mantiene de generación en generación a través de una serie de instituciones que abarcan desde el mercado, la empresa, la familia o la escuela, hasta partidos políticos o sindicatos.

Las empresas que componen el distrito industrial no están agrupadas de forma accidental, sino que cada una de ellas está especializada en una sola fase, o en unas pocas, de los procesos de producción característicos del distrito. Por tanto, estaríamos ante una plasmación, en un ámbito territorial concreto y claramente delimitado, de un proceso de división del trabajo. Ésta estructura empresarial no es aplicable a cualquier proceso productivo, destacando aquéllos cuya demanda final es variable y diferenciada tanto en el tiempo como en el espacio ${ }^{14}$.

El distrito dispone, además, de una serie de mecanismos internos que reasignan constantemente y de forma automática sus recursos humanos en función de las circunstancias. Así, la movilidad de los trabajadores dentro de las distintas empresas

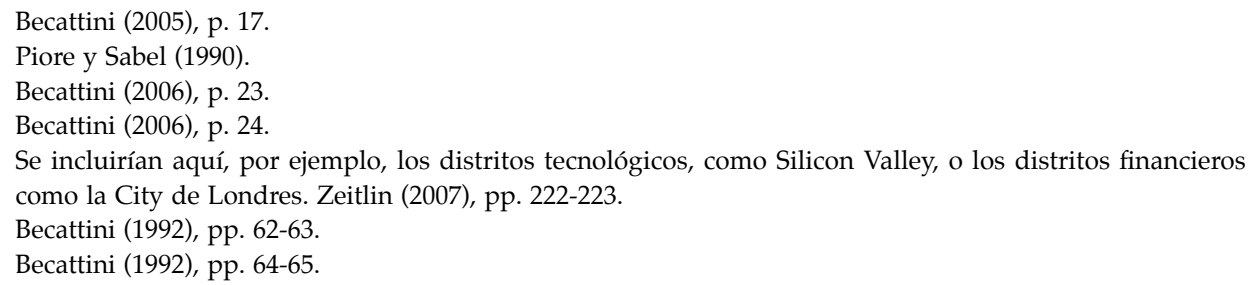


del distrito hace que su especialización no se pierda y siga formando parte de los activos del distrito, facilitando, además, la transmisión de conocimientos de una empresa a otra. En este contexto, resulta también sencillo para las empresas efectuar adecuadamente la evaluación de los trabajadores al estar éstas integradas en una red de relaciones comunitarias que facilita la obtención de información.

Los empresarios del distrito también tendrán unas características peculiares. Basándose en el ejemplo de los impannatori de Prato, existirían lo que Becattini denomina empresarios puros; es decir, empresarios que operan a modo de intermediarios entre el mercado mundial y las dinámicas internas del distrito. Estos empresarios, tras analizar las potencialidades que ofrece el mercado y apoyándose en la amplia gama de posibilidades productivas que ofrece el distrito, diseñan un proyecto de producto para ser lanzado al mercado, que será elaborado con la participación de varias empresas de fase. Por tanto, estos empresarios puros mantienen una posición de equilibrio entre el mercado y el distrito ${ }^{15}$. A este conjunto formado por trabajadores, empresarios de fase y empresarios puros habría que sumar el trabajo a domicilio y el trabajo a tiempo parcial que constituyen, según Becattini, el lazo principal entre la actividad productiva y la vida cotidiana del distrito.

Uno de los atributos característicos del distrito es, sin duda, el conjunto de mecanismos y reglas, escritas o no, que regulan la competencia interna del distrito y que hacen que ésta se combine con una cooperación semiconsciente y semivoluntaria entre los miembros del mismo. Esta coexistencia de la competencia y la cooperación sería una consecuencia de la forma especial en que el sistema sociocultural penetra y estructura el mercado de distrito ${ }^{16}$. Entre estas reglas, destacan sin duda, las relativas al mercado interno de bienes y servicios más utilizados en el distrito, como los productos de fase y los servicios especializados de empresas. Los precios de estos productos estarán determinados no sólo por la coyuntura nacional e internacional, y las circunstancias del mercado local, sino también por la influencia estabilizadora de las instituciones locales ${ }^{17}$. Piore y Sabel destacan también la función ejercida por las autoridades públicas, como los Ayuntamientos, quienes asumían este papel estabilizador regulando las relaciones entre los diferentes agentes del distrito o potenciando la

15 Becattini advierte en éste sentido del peligro de la cosmopolitización de estos empresarios, dejando de ser agentes puros de distrito y pasando a convertirse en intermediarios puros al incorporar nuevas producciones, ajenas al distrito, a su catálogo de productos. En la medida que se diluyen los vínculos con el distrito y aumentan los que mantiene con sus clientes, estas empresas se convierten en "oficinas de compras". Becattini (1992), p. 69.

16 Así, por ejemplo, es necesario, para que el distrito funcione como tal, que quienes resulten perdedores en el juego de la competencia tengan la oportunidad de reincorporarse al sistema y seguir compitiendo. En este sentido, Becattini resalta el importante el papel que juega la existencia de un mercado de maquinaria de segunda mano que facilita a los pequeños empresarios la decisión de mantenerse en el negocio. Becattini (1992), p. 72.

17 Conformarían "un híbrido extraño entre los precios "políticos" y los de mercado". Becattini (1992), p. 72. 
creación de organismos que favorecieran el desarrollo del mismo ${ }^{18}$. Entre estos organismos que facilitan el desarrollo de las capacidades del distrito estarían las instituciones de crédito local ${ }^{19}$, las instituciones educativas y los centros de investigación tecnológica ${ }^{20}$. Pero, sin duda, la principal cualidad de los distritos industriales, y origen de su competitividad, reside en su capacidad de adaptación. La existencia de productores de fase y trabajo a domicilio permite a los empresarios puros reorganizar la producción de forma rápida y sencilla, ajustándola a las variaciones que se producen en el mercado ${ }^{21}$. Las pautas de subcontratación de las empresas del distrito se modifican, del mismo modo, al compás de los cambios en la demanda. Así, empresas que en una coyuntura favorable deben subcontratar parte de la producción ante el exceso de demanda pueden pasar, en otro contexto, a convertirse en empresas subcontratadas o a verse en la necesidad de vender su maquinaria y abandonar el negocio. De esta forma, la personalidad de obrero, contratista o empresario varía en función de la coyuntura y pude darse el caso de que una persona pase por todos esas situaciones varias veces a lo largo de su ciclo vital ${ }^{22}$.

Eibar y su industria armera han sido mencionados como un ejemplo clásico de distrito industrial y, a lo largo de este artículo, trataremos de verificar el grado de cumplimiento en esta localidad guipuzcoana de las características asignadas a los distritos industriales por la literatura especializada. Para ello, en Eibar, deberíamos encontrarnos con una concentración de pequeñas y medianas empresas de fase especializadas en unos pocos sectores, con un importante recurso a la subcontratación tanto vertical como horizontal. También deberíamos constatar la existencia de instituciones que formen la mano de obra y fomenten la difusión del conocimiento, así como la existencia de mecanismos de cooperación entre las empresas. Por último, es necesaria la existencia de un sistema de valores comunes, una cultura de confianza y un sentimiento de pertenencia al distrito entre todos los agentes del $\mathrm{mismo}^{23}$.

\section{Eibar, evidencias de un distrito industrial marshalliano}

El origen de la industria armera de Eibar se encuentra en las antiguas Reales Fábricas instituidas por la Corona en las provincias de Guipúzcoa y Vizcaya para asegurar el suministro de armamento a sus ejércitos durante el Antiguo Régimen.

\footnotetext{
Piore y Sabel (1990), pp. 50-52.

Becattini (1992), p. 74.

Valdaliso y López (2000), p. 110.

Becattini (1992), p. 73.

Piore y Sabel (1990), pp. 51.

Valdaliso y López (2000), pp. 324-325.
} 
Estas fábricas no constituían más que unos meros centros administrativos donde funcionarios reales se encargaban de verificar el cumplimiento tanto cualitativo como técnico de los encargos realizados por el Estado. En el caso de las armas de fuego de la fábrica de Placencia de las Armas-Soraluze, estos encargos se efectuaban a través de asentistas que negociaban directamente con los representantes de los gremios armeros (cañonistas, llaveros, cajeros y aparejeros) la subcontratación de las piezas y operaciones necesarias para construirlas, repartiendo éstos la producción asignada entre los talleres de los municipios de la zona (Eibar, Elgoibar, Ermua, Elgeta, Zaldibar, etc. $)^{24}$.

Tras la Guerra contra la Convención (1793-1794), en que la provincia de Guipúzcoa fue fácilmente ocupada y la localidad de Eibar saqueada por las tropas francesas, quedó en evidencia la escasa idoneidad estratégica del emplazamiento. Esta situación llevó a la Corona a tomar la decisión de crear una nueva Fábrica en Oviedo, establecimiento que fue imponiéndose a Placencia como destinatario de los encargos reales. El declive de la fábrica de Placencia a lo largo del siglo XIX fue cada vez más acusado hasta su definitivo cierre en 1865, condicionado en gran medida por la liberalización de esta actividad industrial a partir de 1860 . La desaparición del sistema gremial fue el detonante del crecimiento de la ya incipiente industria privada de armas que alcanzó un enorme desarrollo en años posteriores $^{25}$.

El definitivo despegue de la industria armera de Eibar se inició en la década de los 80 impulsado por varios factores ${ }^{26}$. La última guerra carlista (1872-1876) tuvo efectos determinantes en el devenir posterior de la industria, ya que el Estado, receloso de potenciar una industria de carácter militar en una región donde el alzamiento carlista había adquirido gran intensidad, prefirió dotar a sus tropas de armas fabricadas en la fábrica de Oviedo y, en caso de necesidad, importarlas del extranjero ${ }^{27}$. Esta situación llevó al sector a especializarse en armas destinadas al mercado civil localizándose la mayor parte de las empresas en Eibar que pasó a ser, a partir de entonces, el principal núcleo urbano de la zona armera. La mayor integración en la economía nacional e internacional favorecida por la instalación de una estación de telégrafo (1883) y la construcción de un ramal del ferrocarril (1887) facilitó el

24 La producción vasca de la época abarcaba, además de las armas de fuego, la fabricación de armas blancas y elementos defensivos como rodelas y coseletes que se elaboraban en otras localidades como Durango, Tolosa o Arrasate-Mondragón. Para la industria armera de esta época ver Azpiazu (2002), Calvó (1997), Carrión (2000), Larrañaga (1981), Larrañaga (2001), Urdangarin, Izaga y Lizarralde (1994).

25 Calvó (1993).

26 Goñi (2007), pp. 392-400.

27 Sí que se hizo algún encargo de revólveres con destino al ejército a fábricas de Eibar, como los obtenidos por Orbea Hermanos, que, siendo importantes para la empresa, resultaban cuantitativamente insignificantes para el conjunto del sector. 


\section{CUADRO 1}

PRODUCCIÓN TOTAL DE ARMAS EN EIBAR Y ESTRUCTURA POR TIPOS EN 1881, 1891, 1901 Y 1909

\begin{tabular}{|c|c|c|c|c|c|c|c|c|}
\hline \multirow{2}{*}{ Tipo de arma } & \multicolumn{2}{|c|}{1881} & \multicolumn{2}{|c|}{1891} & \multicolumn{2}{|c|}{1901} & \multicolumn{2}{|c|}{1909} \\
\hline & n. ${ }^{\circ}$ & $\%$ & n. ${ }^{\circ}$ & $\%$ & n. ${ }^{\circ}$ & $\%$ & n. ${ }^{\circ}$ & $\%$ \\
\hline Escopetas de todas clases & 34.457 & 25,9 & 39.004 & 24,8 & 62.649 & 23,2 & 44.492 & 8,9 \\
\hline Pistolas* & 77.066 & 57,8 & 51.257 & 32,6 & 32.072 & 11,9 & 25.747 & 5,1 \\
\hline Revólveres & 21.097 & 15,8 & 65.434 & 41,7 & 173.587 & 64,2 & 429.308 & 85,7 \\
\hline \multicolumn{9}{|c|}{ Fusiles, cartuchos y tercerolas } \\
\hline Remington & 598 & 0,4 & 1.345 & 0,9 & 1.954 & 0,7 & 1.420 & 0,3 \\
\hline Total de la producción & 133.218 & 100 & 157.040 & 100 & 270.262 & 100 & 500.967 & 100 \\
\hline Índice & & 100 & & 118 & & 203 & & 376 \\
\hline
\end{tabular}

* Se refiere principalmente a pistolas de uno o dos tiros. Las pistolas automáticas comenzarán a fabricarse en el siglo $x x$.

Fuente: Mujica (1908).

acceso de los productores eibarreses a un mercado en el que la demanda de armas cortas estaba atravesando una coyuntura enormemente favorable. Desde el punto de vista de la oferta favoreció también la expansión del sector la introducción de la electricidad, que permitió superar las limitaciones productivas que hasta entonces habían impuesto la energía hidráulica y el vapor ${ }^{28}$. La producción, sostenida principalmente por la venta de revólveres, creció hasta cotas insospechadas en el transcurso de unos pocos años.

Pero, indudablemente, gran parte del éxito de la industria armera vasca fue su peculiar organización industrial, que le permitió adaptarse con facilidad a las circunstancias y competir en los mercados internacionales, donde debieron centrar sus esfuerzos habida cuenta de las escasas dimensiones del mercado interior. La elevada importancia de las exportaciones en el total de las ventas, con una proporción cercana al 90 por ciento, ha sido una de las características que también han acompañado a la industria armera a lo largo de su historia, atributo que también se asocia a la dinámica de los distritos industriales ${ }^{29}$.

\footnotetext{
28 Catalán (1990).

29 Los distritos industriales de Lyon y Solingen, por ejemplo, dominaron durante décadas el mercado europeo de la seda y la cuchillería respectivamente (ver Poni, 1997; Cottereau, 1997 y Boch 1997), y el distrito industrial de maquina herramienta de Cincinatti también exportó una parte significativa de su producción (Scranton, 1997, pp. 197-199). También en España los distritos industriales han mostrado un importante perfil exportador como, por ejemplo, los actuales distritos valencianos del calzado (Miranda, 2005) o la cerámica (Budí, 2008). Para la internacionalización de la industria armera vasca ver Goñi (2009a y 2009b).
} 


\subsection{Características del producto y estructura del sector}

La producción de armamento con destino al mercado civil puede dividirse en dos subsectores claramente diferenciados. Por un lado, nos encontramos con las armas largas constituidas principalmente por las utilizadas para la caza, y por otro, las armas cortas, de menor valor añadido que las anteriores, en las que se incluyen los revólveres y las pistolas. Las características de la demanda de cada uno de estos productos responden también a distintos elementos y motivaciones, que han tenido, sin duda, una gran influencia en la estructura organizativa del sector. Así, las primeras, debido a las superiores exigencias de calidad y cualificación de la mano de obra, presentaban mayores dificultades para su fabricación en serie y su manufactura mantuvo en todos los centros productores europeos un sistema de producción casi artesanal, predominando el trabajo a domicilio ${ }^{30}$. Las armas cortas, en cambio, no estando sujetas a tales exigencias, se prestaban más fácilmente a la estandarización y a la producción en masa.

Lo que caracterizó a la industria armera vasca fue, al contrario que en la industria americana (Colt, Smith $\mathcal{E}$ Wesson) o en la belga (Fabrique Nationale d'Armes de Guerre, FN), la inexistencia de grandes fábricas dedicadas a la producción en serie a pesar de que la producción de armas cortas era predominante (Cuadro 2). La fabricación de armas en Eibar seguía manteniendo una estructura similar a la que históricamente había existido desde la época de las Reales Fábricas, pero ahora, el papel de contratista era ejercido por ciertas empresas localizadas, principalmente, en la villa de Eibar. Estas compañías, poseedoras de patentes y marcas, subcontrataban la fabricación de piezas y la realización de ciertas operaciones a talleres de la localidad para, luego, efectuar el montaje final en sus propias instalaciones ${ }^{31}$. La labor de estas empresas montadoras era la que Becattini asigna a los empresarios puros del distrito, es decir, partiendo del conocimiento de las capacidades del distrito y las posibilidades del mercado, diseñaban un proyecto de producto (un revólver con una marca en concreto) y distribuían las operaciones entre los talleres de la zona (incluido el suyo propio) $)^{32}$.

Estas relaciones de subcontratación no se limitaban a un solo tipo de producto ni eran exclusivas de una tipología de empresa particular. Se han detectado evidencias de empresas montadoras ejerciendo labores de empresa de fase, por tanto, las relaciones de subcontratación no se producían en un sentido único y podían ser

\footnotetext{
Éste sería el caso de Lieja, principal productor europeo de armas de fuego. Gaier (1996).

Echevarria (1990), p. 19.

Esta estructura es similar a la de otros distritos europeos de origen tradicional como el de la industria sedera de Lyon (Cottereau, 1997, pp. 81-87) o la cuchillería de Solingen (Magnusson, 1994, pp. 100-106; Boch, 1997, pp. 156-159).
} 


\section{CUADRO 2}

EL DISTRITO INDUSTRIAL DE EIBAR A COMIENZOS DE 1914 (EMPRESAS Y NÚMERO DE OBREROS)

\begin{tabular}{|c|c|c|c|c|c|}
\hline \multicolumn{2}{|c|}{ Fabricantes de escopetas } & \multicolumn{2}{|l|}{ Fabricantes de revólveres } & \multicolumn{2}{|c|}{$\begin{array}{c}\text { Fabricantes de revólveres } \\
\text { y pistolas }\end{array}$} \\
\hline Aguirre hnos. y Aranzábal & s.d. & \multirow{30}{*}{$\begin{array}{l}\text { Orbea y Cía } \\
\text { Trocaola, Aranzábal y Cía } \\
\text { Antonio Errasti } \\
\text { Juan Baut. Arrizabalaga } \\
\text { Arizmendi y Zulaica } \\
\text { Casimiro Santos } \\
\text { Pedro Elcorobarrutia } \\
\text { Hijos de P. Joaristi } \\
\text { Aguirre, Zamácola y cía. } \\
\text { Hijos de José J. Aldazabal } \\
\text { Macario Echeverría } \\
\text { Salvador Aróstegui } \\
\text { Ramón Urigüen } \\
\text { Faustino Gallastegui } \\
\text { Aróstegui y Echaniz } \\
\text { Lizarriturri, Larrañaga y } \\
\text { Lascurain } \\
\text { Basilio Marcaide } \\
\text { Leon Arizmendi } \\
\text { Basauri y cía } \\
\text { Nicasio Areitio-aurtena } \\
\text { Alejo Bolumburu } \\
\text { Domingo Ojanguren } \\
\text { Isidro Arizmendi e hijos } \\
\text { Pedro Tomás Unceta }\end{array}$} & \multirow{30}{*}{$\begin{array}{r}404 \\
130 \\
50 \\
28 \\
30 \\
1 \\
16 \\
50 \\
23 \\
125 \\
25 \\
20 \\
3 \\
8 \\
10 \\
\\
20 \\
\text { S.d. } \\
20 \\
4 \\
5 \\
6 \\
6 \\
26 \\
10 \\
\end{array}$} & \multirow{7}{*}{$\begin{array}{l}\text { G.A.C. } \\
\text { Arizmendi y Goenaga } \\
\text { Tomás Urizar y Cía } \\
\text { Gabilondo y Urresti } \\
\text { Tomás Arzubia } \\
\text { Azcoaga, Aranceta y Cía. }\end{array}$} & \multirow{6}{*}{$\begin{array}{r}200 \\
125 \\
30 \\
50 \\
24 \\
30\end{array}$} \\
\hline Victor Sarasqueta & 63 & & & & \\
\hline Victor Aramberri e hijos & 50 & & & & \\
\hline Manuel Bereciartúa & 3 & & & & \\
\hline José M. Lecumberri & 4 & & & & \\
\hline Domingo San Martín & 3 & & & & \\
\hline Máximo Zumárraga & 2 & & & & \\
\hline Lauscurain & 9 & & & \multicolumn{2}{|l|}{ Fundiciones } \\
\hline Hijos de P. Guisasola & 2 & & & & \\
\hline Blas Salaverría & 3 & & & Fundición "Estrella" & 40 \\
\hline Domingo Aramberri & 4 & & & Fundición "Aurrera" & 58 \\
\hline Juan José Sarasqueta & 10 & & & Fundición “Azcuaga” & 16 \\
\hline \multicolumn{2}{|l|}{ Fabricantes de pistolas } & & & \multicolumn{2}{|l|}{ Otros } \\
\hline Echeverría hnos. & 48 & & & Forja de Domingo Aris- & \\
\hline Beistegui hnos. & 40 & & & tondo & 12 \\
\hline Martín A. Bascaran & 30 & & & Forja de Martín Errasti & 8 \\
\hline Bonifacio Echeverría & 40 & & & Forja de P. Aristondo & 10 \\
\hline Luis Crucelegui & 18 & & & Orozco y Astaburuaga & 4 \\
\hline Isidro Gastañaga & 50 & & & Zamácola hnos. & 10 \\
\hline Francisco Alberdi & 18 & & & Probadero & 4 \\
\hline Mendicute, Sarasqueta y & & & & & \\
\hline Cía. & 16 & & & & \\
\hline Victor Bernedo & 38 & & & & \\
\hline Erquiaga, Muguruza y Cía. & 30 & & & & \\
\hline Royal Vincitor & 33 & & & & \\
\hline Anguera, Loyola y Cía. & 40 & & & & \\
\hline Gregorio Bolumburu & 26 & & & & \\
\hline Arteagagoitia y Retolaza & 20 & & & & \\
\hline Miguel Aldazabal & 8 & & & & \\
\hline Pedro Urcelay & 20 & & & & \\
\hline
\end{tabular}

\section{Resumen}

\begin{tabular}{lcc}
\hline \multicolumn{1}{c}{ Actividad } & $\mathbf{N .}^{\circ}$ de empresas & $\mathbf{N}^{\circ}{ }^{\circ}$ de obreros \\
\hline Escopetas & 12 & 150 \\
Pistolas & 16 & 475 \\
Revólveres & 24 & 1020 \\
Revólveres y pistolas & 6 & 459 \\
Fundiciones & 3 & 114 \\
Otros & 6 & 48 \\
\hline Total de empresas armeras: & & $\mathbf{5 8}$ \\
\hline N. ${ }^{\circ}$ de obreros & $\mathbf{2 . 1 0 4}$ \\
\hline Otras establecimientos: & $\mathbf{9}$ \\
\hline N. ${ }^{\circ}$ de obreros & $\mathbf{1 6 2}$ \\
\hline Fuente: Archivo Municipal de Eibar, sign. B 51.1. \\
\hline
\end{tabular}


tanto verticales como horizontales ${ }^{33}$. En ocasiones resulta complicado discernir si estas empresas eran auténticos fabricantes o simples comercializadores. Algunos empresarios ni siquiera disponían de un taller y encargaban la fabricación de sus armas a otro empresario de la localidad, quien a su vez subcontrataba la producción. Son muchos los ejemplos de este tipo de actividad ${ }^{34}$, siendo realmente significativo el caso de Gabilondo y Urresti quien, durante la Primera Guerra Mundial, disponiendo únicamente de una marca, RUBY, y un pequeño taller en Eibar presentó una pistola ante las autoridades francesas que fue elegida por éstas como modelo estándar para sus tropas ${ }^{35}$. Debido a las dimensiones del encargo recibido, esta empresa decidió instalarse en la vecina Elgoibar para iniciar la fabricación de este modelo, pero viéndose incapaz de afrontarlo, hubo de subcontratar parte de la producción de pistolas completas a talleres de Eibar, Elgoibar y Gernika-Lumo ${ }^{36}$. La enorme demanda de pistolas automáticas hizo que las especificaciones técnicas exigidas a Gabilondo y Urresti se extendieran también al resto de fabricantes que, independientemente del contrato suscrito por aquélla, comenzaron a recibir importantes encargos. Así, la pistola RUBY acabó convirtiéndose en el producto característico del distrito industrial de Eibar, por lo que también es denominada pistola tipo Eibar ${ }^{37}$.

Becattini indica, entre las características asociadas a los distritos industriales, la necesidad de que exista un producto representativo del distrito. Bajo el paraguas de esta imagen se diluye la identidad de las empresas individuales y sirve para que el distrito se distinga de otros centros productores. La incapacidad de las empresas del sector armero vasco para mantener la relación entre calidad y precio que ofrecían las grandes fábricas europeas y americanas fue la causa de que la capacidad adaptativa del distrito industrial se convirtiera en la base de su competitividad internacional. Así, podían ofrecer una gama mucho más amplia de productos, en series más cortas pero ajustadas a los gustos de los clientes, algo que las grandes empresas tenían mayores dificultades en conseguir. Pero la tendencia de la industria de Eibar a especializarse en la fabricación de armas cortas de calidad media y baja, hizo que el

33 Así, por ejemplo, Esperanza y Unceta durante la Primera Guerra Mundial encargó la fabricación de cachas para sus pistolas a Orbea y Cía., la mayor empresa de la industria armera por aquel entonces. Correspondencia de Esperanza y Unceta. Archivo Gernikazarra (AG en adelante).

34 Goñi (2008), pp. 214-225.

35 En este caso concurren algunas contradicciones, pues mientras según la matrícula industrial (Calvó, 1997, p. 204-205) Gabilondo y Urresti declaraba tener ocho operarios en su taller de Eibar en 1914, los datos procedentes del archivo de Eibar que se muestran en el cuadro 2 nos indican que tenía 50 obreros a su cargo.

36 El gobierno galo hizo un primer encargo de 10.000 pistolas al mes, incrementándolo hasta una cantidad de 30.000 mensuales cuatro meses más tarde. Antaris (2001), p. 91.

37 Durante la Primera Guerra Mundial se alcanzaron las mayores cotas de producción de la industria armera vasca, vendiendo las empresas de Eibar, en torno a 1.600 .000 armas cortas a los países beligerantes. Goñi (2007), pp. 409-416. 
producto representativo del distrito se convirtiera en una especie de estigma que acompañó a las armas españolas en los mercados exteriores. Esta percepción negativa perjudicaba sobre todo a aquellas empresas que trataban de competir con armas de mayor calidad, y fue fuente de preocupación, como veremos más adelante, para todos aquellos que actuaban con conciencia de distrito.

\subsection{El papel de los sindicatos}

Uno de los factores que jugó un papel determinante en el mantenimiento de las dinámicas de distrito fue, sin duda, la actuación de los trabajadores y sus asociaciones, que ejercieron una importante labor reguladora además de ser el origen de numerosas iniciativas de cooperación. Su principal función, en cualquier caso, se centró en el establecimiento de los salarios y el control de su cumplimiento.

La tradición gremial de la industria armera de Eibar fue fundamental para que, desde los inicios de la libertad de industria y ante las presiones de las empresas montadoras, los obreros tendieran a asociarse en defensa de sus intereses siendo su primer éxito el establecimiento de unas tarifas comunes y la regulación del ingreso de los aprendices en los talleres ${ }^{38}$. La presencia de estas sociedades de oficio fue importante en el ramo de la escopetas donde el concurso de obreros cualificados resultaba imprescindible, pero la posterior preponderancia del arma corta en la industria eibarresa, más propensa, como ya ha sido comentado, a la mecanización, hizo que estos sindicatos de oficio perdieran su influencia agrupándose la mayoría de los trabajadores en el denominado Sindicato de Obreros Pistoleros ${ }^{39}$. El incipiente movimiento sindical eibarrés no hizo más que acrecentar entre los empresarios el interés por la mecanización de la producción reduciendo, así, la importancia que los operarios más especializados tenían en el proceso de fabricación, y, por tanto, su influencia en la toma de decisiones empresariales. Estos movimientos patronales fueron el origen de los primeros conflictos laborales en Eibar, pues la primera huelga se produjo cuando Quintana Hermanos, una firma mexicana importadora de armas que decidió montar una planta con capital propio en Eibar, trató de imponer sus criterios a los trabajadores ampliando la jornada laboral, reduciendo los salarios y suprimiendo el trabajo a destajo, algo considerado entonces una prerrogativa de los armeros eibarreses ${ }^{40}$.

Otro caso en el que quedó en evidencia el importante papel que los sindicatos jugaron en la creación y mantenimiento de unas reglas comunes en el interior del

\footnotetext{
$38 \quad$ Echevarria (1990), pp. 21.

39 “... que así se llamaba por decirse así de los honrados maestros y oficiales de aquel gremio antes del encanallamiento gramatical sobrevenido a la palabra..." Echevarria (1990), p. 308.

Echevarria (1990), p. 24.
} 
distrito fue el del traslado de la sociedad J. Esperanza y P. Unceta a la localidad vizcaína de Gernika-Lumo ${ }^{41}$. Esta empresa decidió en 1913 desplazarse a otra población ante la imposibilidad, por falta de espacio según la versión oficial, de montar una nueva fábrica en Eibar ${ }^{42}$. Tras varios intentos infructuosos, finalmente decidieron trasladarse a la villa vizcaína donde, gracias a la intervención de algunos políticos y empresarios de aquella provincia, habían logrado la cesión gratuita de una fábrica de nueva planta. Todo lo relativo al traslado hubo de ser negociado con el Sindicato de Obreros Pistoleros, destacando entre sus peticiones que en el nuevo emplazamiento fueran respetadas las condiciones laborales vigentes en Eibar ${ }^{43}$. Pero las causas del traslado no estaban relacionadas únicamente con problemas de espacio, sino también con el deseo de los empresarios de escapar del control sindical. Un año antes de irse a Gernika-Lumo, mientras estudiaban la posibilidad de llevar sus instalaciones a Vitoria, Juan Esperanza, uno de los socios de la empresa, se vanagloriaba de haber conseguido, gracias a la utilización de maquinaria moderna, reducir la necesidad que tenían de los armeros especializados confesando además que:

“una de las causas de aislar nuestra industria de las demás estriba precisamente en que fuera de aquí podríamos mantener secretos muchos procedimientos industriales que aquí nos alcanzan con facilidad por la excesiva familiaridad de las gentes y por la escasez de locales para su aislamiento" ${ }^{\prime 4}$.

Esta actitud contraria a los trabajadores especializados no tardó en aflorar y, a los pocos meses del traslado, se inició una huelga en la empresa ${ }^{45}$. El origen del conflicto estuvo en el comportamiento de un obrero que, tras pasar unos días en Eibar visitando a su familia con permiso de los patronos, se presentó en la fábrica con un día de retraso aduciendo haber adelantado el trabajo correspondiente a aquel día. Al regresar, se encontró con que su puesto estaba siendo ocupado por un sobrino de Juan Esperanza ${ }^{46}$ y que a él, que hasta entonces había estado trabajando a destajo se le colocaba en un puesto de trabajo a jornal, viéndose reducidos sus ingresos diarios de 8 pesetas a $6^{47}$. Esta medida se enfrentaba directamente con una de las

41 Gernika-Lumo se encuentra a unos 40 kilómetros de Eibar.

42 ASTRA, Unceta y Cía. (1958) pp. 8-11.

43 Carta de J. Esperanza y P. Unceta a la Sociedad de Obreros Pistoleros de Eibar, 11/06/1913, Libro copiador de cartas n. ${ }^{\circ}$. Fondo Esperanza y Unceta. AG.

44 Carta de Juan Esperanza a Julián Ariel Quiroga, Alcalde de Vitoria, 10/05/1912, Libro copiador de cartas $\mathrm{n}^{\mathrm{o}} 2$. Fondo Esperanza y Unceta. AG.

45 Exactamente la empresa reinició su actividad en la nueva fábrica de Gernika-Lumo a comienzos del mes de julio de 1913. El conflicto se inició el 25 de Septiembre de aquel mismo año finalizando un mes después.

46 Éste cobraba 18 reales de jornal.

$47 \quad$ Etxaniz (2000), p. 152. 
tradiciones más arraigadas entre los obreros de Eibar, el trabajo a destajo, que en aquellos años, como ya hemos comentado más arriba, era considerado un derecho intrínseco al oficio armero ${ }^{48}$.

Las relaciones con los patronos ya estaban por aquel entonces bastante deterioradas, no en vano, la empresa había intentado ya, sin éxito, cambiar la modalidad de pago de otros obreros y la extensión de un rumor que indicaba que iban a ser incorporadas mujeres gerniquesas a los trabajos de maquinas no hizo más que enrarecer aún más el ambiente ${ }^{49}$. El que la empresa se negara a reincorporar al obrero a su puesto de trabajo anterior fue el detonante de la huelga que se saldó finalmente con el regreso de la mayor parte de la plantilla a Eibar, dejando a la compañía en una situación ciertamente precaria. Sin embargo, poco tiempo después, volvió a recuperarse el ritmo de producción mediante la contratación de mano de obra local lo que produjo no poca satisfacción a los empresarios ${ }^{50}$.

Es de destacar el importante papel que la Sociedad de Obreros Pistoleros de Eibar jugó en el sostenimiento de esta huelga, pues, a pesar de haberse trasladado a otra localidad, tanto los obreros como los patronos eran eibarreses y, por tanto, los consideraban miembros de su comunidad. Se hicieron donaciones y suscripciones voluntarias en los talleres para el sostenimiento de las familias de los huelguistas, además de denunciar públicamente a los esquiroles ${ }^{51}$. A su regreso, los obreros de $J$. Esperanza y $P$. Unceta fueron recibidos como auténticos héroes, por haber sabido mantener con dignidad su alto concepto de obreros libres ${ }^{52}$. Por tanto, nos encontramos ante una extensión de la función reguladora del sindicato fuera de su ámbito geográfico, al seguir considerando a los obreros emigrados como miembros de la comunidad.

Pero la actividad de los sindicatos no se redujo únicamente al establecimiento de unas reglas en el mercado laboral interno y a un control del cumplimiento de las mismas. También jugaron un papel importante en otras esferas, que a priori, podrían considerarse fuera de su ámbito de actuación como la creación de la Sociedad Coope-

48 Goñi (2007), p. 401.

49 Etxaniz (2000), p. 149.

50 "Debo participarle que después de tantas calamidades que he pasado en Eibar, me trasladé a Guernica (Vizcaya) hace 10 meses, donde también he sido perseguido por la gente de Eibar llegando en su afán de destruir ésta a la osadía de incitar a los obreros míos a la huelga, careciendo de razones algunas; como resultado de estos conflictos, de 150 obreros que trabajaban sólo me quedaron 6. Más reandando las tareas de nuevo con más bríos que antes hemos llegado ya a la misma marcha de antes; teniendo ya 150 obreros nuevos siendo todos hijos de este pueblo; viniendo a demostrar a los Eibarreses que en ningún modo son indispensables." Carta de Juan Esperanza a Augusto Esteban, Director de la Fábrica Nacional de Trubia (Asturias), 1804/1914, Libro copiador de cartas n. ${ }^{\circ}$ 7. Fondo Esperanza y Unceta. AG.

Etxaniz (2000), p. 154.

Etxaniz (2000), p. 160. 
rativa Alfa $^{53}$. Tras la finalización de la Primera Guerra Mundial la industria armera se vio inmersa en una grave crisis y, ante el crecimiento experimentado por el coste de la vida, los obreros, agrupados ahora en un único sindicato metalúrgico, se declararon en huelga reivindicando un incremento salarial al que los empresarios no se avenían. Poco después, intentando demostrar a los patronos lo injusto de sus planteamientos, los obreros socialistas eibarreses alumbraron la idea de montar una fábrica de revólveres y, con la colaboración del Sindicato Metalúrgico de Vizcaya, consiguieron reunir las 300.000 pesetas de capital necesarias para poner en marcha la Sociedad Cooperativa Alfa ${ }^{54}$. Esta empresa, a pesar de iniciar su andadura con la producción de revólveres, pronto pasó a la construcción y venta de máquinas de coser, producto con el que obtuvo su mayor reconocimiento ${ }^{55}$.

\subsection{Las características de los empresarios}

Una de las características de todos los distritos industriales es la habitual tendencia de los obreros a intentar establecerse por su cuenta ${ }^{56}$. Por esta razón, es bastante común que los patronos de las empresas hayan sido, en sus orígenes, simples operarios que han conseguido prosperar en el negocio llegándose, incluso, a considerar esta circunstancia una condición necesaria para llegar a ser un buen empresario $^{57}$.

Las descripciones existentes de los empresarios armeros y su experiencia vital nos ofrecen una imagen similar para el caso de Eibar. Era frecuente que muchos de ellos se hubiesen iniciado en esta actividad trabajando a domicilio en algún caserío

53 Otro ejemplo sería la oferta que hizo la Casa del Pueblo de Eibar para ayudar en la financiación de los gastos de la carretera al barrio de Aguinaga, obra pública promovida por el Ayuntamiento para dar empleo a los armeros parados durante la crisis de 1914. Los socialistas de Eibar llevaban varios años recaudando fondos para la futura construcción de la Casa del Pueblo y ante los problemas presupuestarios que estaba sufriendo el Ayuntamiento por financiar las obras los concejales socialistas ofrecieron lo recaudado, a modo de préstamo sin intereses. Finalmente esta iniciativa no se hizo efectiva. Actas del Pleno del Ayuntamiento de Eibar de 1914, Archivo Municipal de Eibar (AME en adelante), Sign. A 11.31.

$54 \quad$ Echevarria (1990), pp. 309-311.

55 Para conocer las vicisitudes de esta empresa desde su creación hasta la actualidad ver Iza-goñola (2005).

56 Becattini (2005), p.102. En muchos distritos, además, se fomentaba expresamente esta tendencia con la existencia de edificios de apartamentos en los que se ofrecía a las pequeñas empresas un espacio en el que comenzar su actividad a cambio del pago de una renta, generalmente por el uso de la fuerza motriz. Scranton (1997), p. 245, y Boch (1997), p. 180, nos dan referencia de ello para el caso del distrito joyero de Providence, Rhode Island, y el cuchillero de Solingen, respectivamente. En el caso de Eibar existen indicios de la existencia de instalaciones de este tipo pues, Ignacio Ibarzabal, uno de los principales empresarios de la localidad y propietario de una fábrica cotizó en la matrícula industrial a finales de siglo por el alquiler a varios armeros independientes de la fuerza motriz de un salto de agua de su propiedad. Calvó (1997), pp. 227-228.

$57 \quad$ Becattini (2005), p. 99. 
cercano o colocándose como aprendices en un taller o fábrica de la localidad donde, además de trabajar en la armería, realizaban actividades domésticas a cambio del alojamiento y el sustento ${ }^{58}$. Una vez alcanzada la experiencia suficiente, muchos se independizaban montando un taller con el mínimo de maquinaria (seguramente un torno de segunda mano) para dedicarse a la fabricación de piezas para otros productores. El siguiente paso, en el caso de que el armero contara con la capacidad técnica y económica suficiente, era diseñar su propio modelo, registrar una marca y construir armas completas.

En la mayoría de los casos, estos armeros no disponían de capitales para iniciarse en solitario en el negocio, por lo que tendían a asociarse con otros armeros o comerciantes de la localidad ${ }^{59}$. Normalmente uno de los socios aportaba sus conocimientos técnicos, por lo que solía encargarse de la dirección del taller, mientras que el otro se responsabilizaba principalmente de la gestión administrativa de la sociedad y la correspondencia. Dos de las empresas más representativas de la industria armera vasca a lo largo del siglo xx, Esperanza y Unceta y Bonifacio Echeverría, son claros ejemplos de este modelo. Según las escrituras de la primera de ellas, fundada en 1908, a Juan Esperanza ${ }^{60}$, mecánico de profesión, se le asignaba la dirección técnica del taller, mientras que al otro socio, Juan Pedro Unceta, quien a pesar de disponer de cierta experiencia como armero era conocido por su actividad como comercial ferretero en Eibar, se le encargaba la dirección comercial ${ }^{61}$. En sus comienzos se dedicaron a la mecanización de piezas para otras empresas eibarresas pero, tres años después, construían ya pistolas automáticas completas con las que obtuvieron un gran éxito comercial ${ }^{62}$. La empresa Bonifacio Echeverría tuvo su origen en otra, denominada Echeverría Hermanos, constituida en 1902 por los hermanos, Bonifacio y Julián Echeverría, destacando este último por su actividad como diseñador de armas. Sus patentes de pistolas, las primeras STAR, fueron explotadas por la socie-

\footnotetext{
58 Echevarria (1990), p. 20.

59 Casi todas eran sociedades regulares colectivas o comanditarias y eran constituidas con capitales bastante modestos, parte de los cuales estaban constituidos por máquinas que alguno de los socios traía consigo de algún fracaso empresarial anterior.

60 “D. Juan Esperanza era aragonés y había llegado a Eibar tras corta estancia en Irún, buscando maestros para su amor por la mecánica y campo para el desarrollo de sus claras ideas. Tras corto aprendizaje, se había impuesto en todos los secretos del arte y había llegado a ser uno de los más distinguidos mecánicos de la localidad. [...] Era fuerte, locuaz, reposado en sus juicios, activo, estudioso y observador." ASTRA, Unceta y Cía. (1958), pp. 6-8.

61 "Tenía su solar en el valle de Arrate y de allí había descendido hasta "la calle" para trabajar como aprendiz artesano en el pequeño taller familiar de uno de sus tíos. Iniciado así en la producción industrial, fue sucesivamente montador de armas, fabricante y exportador de ellas y al final comerciante ferretero y corresponsal bancario. D. Pedro Unceta era menudo, vivaz, parco en palabras, concienzudo, razonador." ASTRA, Unceta y Cía. (1958), pp. 6-8.

62 Esta empresa, años más tarde, comenzó la fabricación de sus pistolas ASTRA con las que fue mundialmente conocida. Antaris (1988).
} 
dad aun después de que abandonara la misma para convertirse en Director de la Escuela de Armería ${ }^{63}$.

Existen varias descripciones sobre empresarios de finales del XIX y principios del $\mathrm{xx}, \mathrm{y}$ casi todas ellas nos muestran a personas con una formación académica básica y unos conocimientos técnicos alcanzados mediante el aprendizaje práctico en el taller ${ }^{64}$. Esto no fue óbice para que todos ellos consiguieran operar en mercados exteriores, a pesar de que muchos de ellos desconocieran prácticamente el castellano $^{65}$. Sin duda, la normalidad con la que se afrontaba la exportación en Eibar, algo que podríamos calificar, parafraseando a Marshall, como "ambiente industrial exportador" facilitaba el que estos empresarios se lanzaran sin complejos a la competencia internacional. En cualquier caso, este tipo de empresarios corresponde, en gran parte, a las primeras generaciones de armeros. Posteriormente el nivel formativo de muchos de ellos se incrementó notablemente, y en caso contrario, el distrito ofrecía recursos humanos suficientes para solventar, mediante la contratación o asociación, los posibles obstáculos que esta falta de formación pudiera provocar ${ }^{66}$.

Otro de los aspectos que Marshall destacaba del funcionamiento interno de los distritos estaba relacionado con la relación entre los empresarios y sus empleados, entre los que a menudo existían relaciones de amistad ${ }^{67}$. En el caso de Eibar, el hecho de que la mayor parte de los empresarios hubiera comenzado su actividad desde el estadio más bajo del proceso productivo, como simples aprendices, ejercía un efecto balsámico sobre los conflictos laborales que, aun siendo enconados, nunca se saldaron violentamente a pesar de la enorme disponibilidad de $\operatorname{armas}^{68}$.

63 Antaris (2001).

64 Ver Echevarria (1990), pp. 90, 109, 138, 194, 378.

65 "El invierno pasado, un día del mes de enero, encontramos inesperadamente, en las calles de Madrid, al propio Sarasqueta, el armero habilísimo de Eibar, [...] Iba Sarasqueta acompañado de un dependiente del escritorio de su fábrica, D. Joaquín Fernández, que en casos de necesidad le servía de intérprete, porque el armero eibarrés, apenas si conoce el castellano, y no sabe expresarse bien más que en vascuence." Victor Sarasqueta, Cortaberría y Cía. (1904).

66 Toribio Echevarria nos cuenta como él mismo, para poder completar su salario como funcionario municipal, se dedicaba a llevar la correspondencia en francés de un armero de la localidad. Echevarria (1990), p. 320.

$67 \quad$ Marshall (1954), p. 227.

68 Toribio Echevarria nos relata, en este sentido, cómo durante la huelga que llevaron a cabo los armeros eibarreses tras la Primera Guerra Mundial, y tras cuatro meses de conflicto, coincidieron en un mismo restaurante los representantes de los obreros y los principales miembros de la patronal. A pesar de las diferencias, tras los postres, acabaron por juntar las mesas "para continuar la fiesta en común, olvidando por lo que durara el resto de aquel día, no los rencores, que en realidad no existían, sino la hostilidad política y social que nos dividía en la vida ordinaria". Echevarria (1990), p. 315. 


\subsection{Las instituciones por y para el distrito}

Como ya se ha comentado más arriba, las instituciones públicas locales pueden jugar un papel fundamental tanto como agentes reguladores en el interior del distrito como promoviendo la creación de organismos para favorecer su desarrollo. En el caso de Eibar se dieron ambas circunstancias.

\subsubsection{El papel del Ayuntamiento en la cooperación entre empresas}

La preeminencia de la industria armera en la actividad económica del Eibar de comienzos del siglo XX se veía también reflejada en la composición de la corporación municipal donde la mayor parte de los concejales eran conocidos armeros ${ }^{69}$. Así, el pleno del Ayuntamiento se convirtió en un foro de debate donde las opiniones de obreros y patronos confluían siempre que el sector y, por tanto, el distrito, se enfrentaba a alguna dificultad. El Alcalde, además, realizaba una activa labor de intermediación y, en ocasiones, los propios recursos de la institución municipal eran utilizados en favor de los intereses de esta industria. Por ejemplo, el abogado madrileño que el Ayuntamiento tenía contratado para representar al municipio ante las autoridades gubernamentales, dedicó gran parte de su actividad a tratar estos asuntos relacionados con la armería. Por tanto, el Ayuntamiento jugó un papel importante como garante del espíritu del distrito y principal defensor del futuro de la industria, aunque esta actitud no fuera siempre comprendida por el resto de los miembros de la comunidad.

Así, en 1900, siendo por aquel entonces Antonio Iturrioz el máximo dirigente municipal, surgió una fuerte polémica en el Ayuntamiento en torno a una comisión de estudios enviada a París. El detonante de esta expedición fue otra que, formada por obreros y financiada por el Estado, visitó la Exposición Universal de París celebrada en $1901^{70}$. El alcalde consideraba que a un evento como ese era necesario enviar personas con una mayor cualificación y, por ello, poco tiempo después solicitó la creación de una nueva comisión que, financiada por el Ayuntamiento y la Junta del Banco de Pruebas, fuera a París a estudiar las posibilidades que ofrecía un horno eléctrico que allí se estaba experimentando. La proposición se aceptó no sin cierta polémica ya que, ante la designación del alcalde como miembro de la comisión junto a un capitán de artillería, algunos de los miembros de la corporación expusieron que:

Fernández de Pinedo (2005), p. 10.

R.O. de 23 de mayo de 1900 del Ministerio de Agricultura, Industria, Comercio y Obras Públicas. 
“el Ayuntamiento no debe de tomar resolución alguna en el asunto [de la comisión], toda vez que no es de interés general y existen en el pueblo dos fundiciones particulares de hierro maleable, correspondiendo a los interesados en ellas el estudio de los adelantos y mejoras que puedan introducirse en dicha industria, sin que el Ayuntamiento se mezcle en industrial lo que en puridad representaría el acuerdo [la designación del representante municipal en la comisión] que pretende adoptar la Corporación"71.

Una vez trasladado a París y viendo que el horno no cumplía con las expectativas creadas, el alcalde decidió aprovechar el viaje y desplazarse hasta Lieja (Bélgica), principal centro armero de la época, para poder así conocer de cerca las características de su industria armera y determinar de esa manera la estrategia a seguir por la industria eibarresa en el futuro. Mientras el alcalde estuvo ausente, en la prensa local se inició una campaña, instigada principalmente desde el diario socialista Adelante, en la que se ponían en duda los verdaderos intereses y motivos del alcalde para efectuar el viaje. A su regreso Antonio Iturrioz se defendió con ardor de las acusaciones, pero pasados los años, Toribio Echeverría hablaba aún con cierta ironía de su afición por las comisiones y los viajes ${ }^{72}$.

La historia del Ayuntamiento eibarrés durante las primeras décadas del siglo XX está repleta de actuaciones en favor de la industria armera y sería demasiado extenso referir aquí todas ellas, por lo que mostramos un breve resumen de algunas:

- El asunto de las armas retenidas en Turquía. A finales de 1910 el Gobierno Turco prohibió la importación de revólveres con un cañón inferior a los $15 \mathrm{~cm}$ lo que equivalía, en la práctica, a impedir la entrada de todo tipo de revólveres y que trajo como consecuencia la retención en la frontera de gran cantidad de armas procedentes de Eibar y otros países. Se nombró una comisión mixta compuesta por el alcalde y un representante de los industriales que se trasladó a Madrid para tratar con el Ministerio de Estado la resolución del asunto. Además el Ayuntamiento, en representación del conjunto del distrito, trató de establecer ciertos acuerdos con la Unión de Fabricantes de Lieja para obtener, en coordinación con otros centros armeros implicados, una

71 Moción presentada por el Concejal Anguiano en sesión del pleno del Ayuntamiento de Eibar, 17/12/1900. AME. Sign. A11.19.

72 “El personaje más destacado del republicanismo eibarrés de aquella época era don Antonio Iturrioz, alcalde que fue de la villa durante la guerra de Cuba; si no me equivoco, entre 1896 y 1900. [...] Hombre Iturrioz de gran inteligencia, se había hecho con una cultura que tenía sus exigencias y para ver algo del mundo, inventó desde la alcaldía unas fantásticas comisiones a Madrid y a París, alrededor de las cuales sus contrarios los "betarras" promovieron un gran escándalo pueblerino". Echevarria (1990), pp. 28-29. La palabra "betarra" hace referencia a las personas que residían en la parte baja de la localidad de Eibar que eran de tendencia conservadora, mientras que Iturrioz, republicano, era un "goitarra" habitante de la parte alta de la localidad. 
solución satisfactoria al problema. Finalmente, tras las negociaciones realizadas por la Legación de España en Constantinopla, el asunto quedó resuelto con la repatriación de las armas en mayo de $1911^{73}$.

- La crisis de 1914. El comienzo de la Primera Guerra Mundial generó una de las crisis de mayor gravedad a la que tuvo que enfrentarse la industria armera. Ya se habían observado algunas dificultades durante los primeros meses del año pero fue el inicio del conflicto el que llevó a la localidad a una situación desesperada. Las restricciones sobre el comercio de armas y el hecho de que las instituciones financieras se abstuvieron de efectuar giros, provocó que muchos de los negocios y pagos pendientes no se materializaran. El desempleo creciente llevó al Ayuntamiento a poner en funcionamiento todos los mecanismos de los que disponía para evitar la dispersión de la mano de obra que sería necesaria cuando la situación se normalizase: se abrieron cocinas económicas, se recuperó un viejo proyecto de construcción de una carretera, se emitió papel moneda para pagar a las brigadas de trabajadores, se municipalizó la banda de música para que sus integrantes, también armeros, no abandonasen el municipio, se negoció un contrato de fabricación de 16.000 revólveres para la Guardia Civil etc. ${ }^{74}$.

- El pleito armero ${ }^{75}$. En 1920 el Gobierno, con intención de reducir los efectos del pistolerismo, aprobó una nueva legislación que restringía enormemente el comercio de armas en España. En aquel momento, en que la coyuntura de los mercados exteriores no era la más favorable, las nuevas disposiciones tuvieron un efecto inmediato sobre las ventas. Los Ayuntamientos de la zona armera, liderados por el de Eibar, iniciaron entonces una campaña, conocida como el Pleito Armero, durante la cual, ante el clamor popular, llegaron a dimitir el conjunto de las corporaciones. La campaña se prolongó durante varios años en los que se hicieron inútiles propuestas al Gobierno para que permitiera la creación de un Trust Armero o que éste recibiera una compensación para poder efectuar una transformación de la industria. Aunque, quizá, la más llamativa de todas las iniciativas adoptadas, fue la proposición al cargo de diputado de Juan Urizar, armero y concejal de Eibar, que consiguió ser elegido por el distrito de Bergara a pesar del caciquismo imperante en la época ${ }^{76}$.

AME Sign. B 51.

Goñi (2007) pp. 407-409.

Eguren (1923).

Indalecio Prieto, relata una divertida anécdota sobre este diputado en su primer día en el Congreso ya que un ujier, viéndole ataviado con una boina y ropa sencilla, le impidió el paso al hemiciclo. "Entre una boina y una cachava. 13 de junio de 1923." Montero (2006). 


\subsubsection{La Escuela de Armería y el Banco de Pruebas}

Las dos iniciativas que partiendo del Ayuntamiento obtuvieron un mayor éxito y que, sin duda, son indicativas del dinamismo de Eibar como distrito industrial armero a comienzos del siglo xx fueron la Escuela de Armería y el Banco Oficial de Pruebas.

\subsubsection{La Escuela de Armería}

Ya desde el siglo XIx había existido en Eibar una Academia de Dibujo ${ }^{77}$ con el objeto de que los niños del municipio aprendiesen a dominar este arte estrechamente relacionado con la industria armera, pues las armas de caza, y en ocasiones también las cortas, son grabadas o damasquinadas ${ }^{78}$ con elaborados dibujos abstractos o figurativos.

Lo que no existía, y cada vez mayor número de voces demandaba a comienzos de siglo, era una institución educativa que ofreciera a los futuros armeros una formación técnica de mayor calidad que la que se obtenía mediante el aprendizaje en el taller ${ }^{79}$. Una moción presentada al pleno del Ayuntamiento de Eibar en 1904 ya hacía referencia a la necesidad de la creación de una institución de este tipo para no limitar la enseñanza a la educación primaria, ya que, teniendo en cuenta las características de la villa, consideraban:

“de gran conveniencia fomentar la enseñanza del dibujo, que tan buenos resultados ha dado, extenderla al dibujo industrial combinada con la mecánica, no sólo en teoría, sino principalmente en la práctica, estableciendo las prácticas del taller para los alumnos a fin de que el aprendizaje industrial se haga por principios y se preparen generaciones de obreros inteligentes y bien adiestrados. Con la enseñanza industrial debe compartir la mercantil, aunque sea el elemental" ${ }^{\prime 0}$.

$77 \quad$ Echevarria (1990), p. 98.

78 Obra de adorno que se hace con filamentos de oro o plata embutiéndolos en ranuras o huecos previamente abiertos en piezas de hierro $\mathrm{u}$ otro metal.

79 Los obreros cualificados son la base de los sistemas productivos flexibles, por lo que asegurar su pervivencia es una garantía para la reproducción de los medios de producción de los distritos industriales. Esta es la razón por la que en todos ellos se ha potenciado la creación de instituciones educativas o, al menos, se han regulado las condiciones del sistema de aprendizaje práctico en los talleres. Scranton (1997), nos ofrece ejemplos de instituciones de este para el caso de la industria textil de Philadelphia o la máquina-herramienta de Cincinatti. En el caso de la industria armera de Eibar, la Escuela de Armería de Lieja fue el principal referente a seguir.

80 Sesión del pleno del Ayuntamiento de Eibar, 07/01/1904. AME. Sign. A11.21. 
Durante la celebración de las fiestas euskaras de 1908 en Eibar, Pablo Alzola, en una conferencia relativa al futuro de la industria armera, también hizo especial hincapié en la necesidad de crear una Escuela de Armería a imagen de la que ya existía en Lieja, pues esa era según su opinión, una de las causas de que la industria de aquella ciudad superara a la eibarresa ${ }^{81}$.

El proyecto de creación de una Escuela de Artes y Oficios, junto con un Museo de Armería, estuvo presente en el ánimo de los dirigentes locales y aparecía frecuentemente entre las iniciativas y mociones relativas a la industria armera que los concejales presentaban a las sesiones del pleno del Ayuntamiento. Pero no fue hasta la sesión de 1 de julio de 1912, cuando se aprobó la moción que daría carta de naturaleza al proyecto definitivo de la Escuela de Armería de Eibar ${ }^{82}$. En esa misma sesión se vislumbró también la forma de implicar a los fabricantes de armas en la financiación de esta entidad, que al fin y al cabo, redundaría en el futuro en beneficio de sus propios intereses al incrementar la cualificación de la mano de obra de la localidad. Por aquel entonces los fabricantes estaban obligados a pagar al Estado un impuesto por cada envío de armas que se realizaba y se propuso solicitar a la Delegación de Hacienda la cesión de la recaudación del mismo para sufragar los gastos del centro ${ }^{83}$.

A pesar de que el Ministerio de Hacienda no opuso objeción alguna a la cesión de la gestión del producto de las guías sobre las armas al Ayuntamiento, la aplicación de este impuesto generó no pocas discusiones entre las autoridades municipales y los fabricantes. El objetivo del Ayuntamiento era añadir a la tasa fija existente otra progresiva en función del valor del arma, mientras que los empresarios preferían que este arbitrio no sufriera modificación alguna ${ }^{84}$. El recurso de alzada que interpusieron ante la Diputación Provincial aducía que el Ayuntamiento no podía variar la tarifa de un impuesto estatal por estar fuera de su competencia. Finalmente, se impusieron los argumentos de la patronal armera y la tarifa no fue modificada.

En estas condiciones, el producto de este impuesto no podía ser suficiente para la puesta en marcha del proyecto (Cuadro 3) por lo que, para su consecución, fue necesario recurrir a otras fuentes de ingresos. Además de la subvención anual otor-

Mújica (1908), pp. 493-496.

Acta de la sesión del pleno del Ayuntamiento de Eibar de 01/07/1912 AME. Sign. A11.29.

Esta imposición estaba compuesta por un visado de 0,10 pesetas por paquete postal, mientras que por las guías y precintado de las cajas se pagaban 0,65 y 0,50 pesetas respectivamente. Es decir, debían pagarse 1,25 pesetas por envío realizado independientemente del número y el precio de las armas. AME Sign. B 51 .

84 “Por cada escopeta Remington, 0,05 ptas; Por cada escopeta de cargar por la boca, 0,02 ptas; Por cada escopeta de retrocarga, 0,04 ptas; Por cada pistola de varios sistemas, 0,02 ptas; Por cada pistola automática 0,05 ptas; Por cada revólver 0,02 ptas." Acta de la sesión del pleno del Ayuntamiento de Eibar de 13/11/1913 AME. Sign. A11.30. 


\section{CUADRO 3}

ESTRUCTURA DE LOS INGRESOS DE LA ESCUELA DE ARMERÍA DE EIBAR (1913-1920)

\begin{tabular}{|c|c|c|c|c|c|c|c|c|}
\hline & 1913 & 1914 & 1915 & 1916 & 1917 & 1918 & 1919 & 1920 \\
\hline Ministerio de Instrucción Pública & $40,6 \%$ & $31,0 \%$ & $30,2 \%$ & $32,7 \%$ & $26,6 \%$ & $25,9 \%$ & $24,9 \%$ & $43,6 \%$ \\
\hline Diputación Provincial de Guipúzcoa & $12,0 \%$ & $9,2 \%$ & $8,9 \%$ & $9,6 \%$ & $7,7 \%$ & $7,6 \%$ & $7,3 \%$ & $6,1 \%$ \\
\hline Guías, Visados etc. sobre armas & $47,4 \%$ & $29,0 \%$ & $25,7 \%$ & $30,3 \%$ & $24,3 \%$ & $23,8 \%$ & $24,9 \%$ & $20,9 \%$ \\
\hline Ayuntamiento & & & & & $22,1 \%$ & $21,6 \%$ & $18,7 \%$ & $16,6 \%$ \\
\hline Ingresos propios & & & & $13,2 \%$ & $14,2 \%$ & $15,7 \%$ & $20,8 \%$ & $11,4 \%$ \\
\hline Remanente año anterior & & $30,8 \%$ & $35,1 \%$ & & $5,0 \%$ & $5,5 \%$ & $3,3 \%$ & $1,4 \%$ \\
\hline \multirow[t]{2}{*}{ Déficit (sufragado por el Ayuntamiento) } & & & & $14,2 \%$ & & & & \\
\hline & $100 \%$ & $100 \%$ & $100 \%$ & $100 \%$ & $100 \%$ & $100 \%$ & $100 \%$ & $100 \%$ \\
\hline Total ingresos & $29.204,75$ & 38.198 & 39.243 & $36.277,42$ & 45.192 & 46.311 & 48.106 & 57.366 \\
\hline
\end{tabular}

Fuente: Memorias de la Escuela de Armería de Eibar. Archivo Municipal de Eibar. Sign. B.1.16.

gada por la Diputación Provincial de Guipúzcoa ${ }^{85}$, Fermín Calbetón, senador vitalicio por Guipúzcoa y, a la sazón, ministro de Fomento, consiguió sendas partidas presupuestarias tanto en el Ministerio de la Guerra ${ }^{86}$ como en el de Instrucción Pública $^{87}$. Gracias a ésta y otras actuaciones, este político guipuzcoano fue depositario del afecto de la localidad y tras su fallecimiento en 1919 siendo ministro de Hacienda, se decidió conceder su nombre a una calle de Eibar.

El reglamento, los Estatutos y las asignaturas a impartir se inspiraron directamente en los modelos de las Escuelas de Lieja y Saint Etienne ${ }^{88}$, referencia obligada en Eibar siempre que se tomaban decisiones estratégicas relacionadas con la industria armera $^{89}$. El primer curso se inició en enero de 1913 aunque, mientras se construía el inmueble que iba a albergarla, la Escuela comenzó su andadura en unas dependencias municipales preparadas provisionalmente para ello ${ }^{90}$. La primera piedra del nuevo edificio se colocó el 6 de enero de 1913 inaugurándose definitivamente el 24 de junio de $1914^{91}$.

El plan de enseñanza diseñado por el profesorado de la Escuela a cuya cabeza se encontraba Julián Echeverría, del que ya hablamos anteriormente y que perma-

85 Memoria de la Escuela de Armería, curso de 1913, p. 7. AME.

8650.000 pesetas anuales. Acta de la sesión del pleno del Ayuntamiento de Eibar, 04/01/1915 AME. Sign. A11.32.

87 12.000 pesetas anuales. Acta de la sesión del pleno del Ayuntamiento de Eibar, 03/05/1915 AME. Sign. A11.32.

88 Memoria de la Escuela de Armería, curso de 1913, p. 9. AME.

89 Para el estudio de la influencia de Lieja y Saint Etienne en la Escuela de Armería de Eibar ver Caballer (2000).

90 Memoria de la Escuela de Armería, curso de 1913, p. 7. AME.

91 Caballer (2000), p. 298. 
neció en el cargo hasta 1936, estaba comprendido por tres cursos teórico-prácticos. En el primero se impartía aritmética, álgebra y dibujo lineal; en el segundo, geometría, dibujo industrial y ejercicios de lima; y, en el tercero, trigonometría, química, física, mecánica aplicada y dibujo al croquis del natural; realizándose también proyectos de fabricación, trabajos manuales aplicados a las armas largas y manejo de máquinas-herramientas ${ }^{92}$.

La Escuela de Armería de Eibar fue determinante en el posterior desarrollo de la industria armera eibarresa al formar a varias generaciones de armeros, muchos de los cuales alcanzaron posteriormente puestos de responsabilidad en las empresas de la localidad. Además, desde esta institución se promovieron importantes proyectos de transformación de la industria, como el de la instalación en Eibar de una gran fábrica de escopetas de caza tras la finalización de la Primera Guerra Mundial. Con este proyecto se pretendía no sólo superar la esperada crisis posguerra sino, también, reducir la dependencia de la industria eibarresa con respecto a las armas cortas, cuyo futuro se presentaba poco halagüeño.

Para la financiación del proyecto Eibar debía aportar 800.000 pesetas del capital social de la nueva empresa mientras que el resto, hasta las 2.500 .000 presupuestadas, sería entregado por capitalistas bilbainos. A pesar de contar con el apoyo del Ayuntamiento en la promoción de la iniciativa, sólo lograron suscribirse acciones por un valor de 156.100 pesetas de las que los fabricantes e industriales aportaron únicamente 92.100. Entre estos no aparece ninguna de las grandes empresas de la localidad que mostraron poco interés por la misma. Así, Julián Aramberri de Víctor Aramberri e Hijos, declinó participar en la comisión creada al efecto por "hallarme en estos momentos ocupado en estudios relacionados con la industria de ésta su casa y no restarme tiempo para dedicarme a otros asuntos ${ }^{\prime 93} \mathrm{o}$ la Industrial Orbea ${ }^{94}$ y Gárate, Anitua y Cía. (GAC), que también rechazaron participar en el proyecto aduciendo estar:

“pendientes las gestiones que llevan a efecto con objeto de conseguir la formación de una Sociedad para la fabricación de ametralladoras en Eibar, y no contando con elementos suficientes para tomar parte en el proyecto presentado mientras no se resuelva el asunto antes indicado de las ametralladoras, suplicó se les sustituya en esta Comisión agradeciendo su nombramiento" ${ }^{\prime 95}$.

\footnotetext{
92 Memoria de la Escuela de Armería, curso de 1913, p. 9. AME.

93 Carta de Julián Aramberri, de Víctor Aramberri e Hijos, al Presidente de la Comisión Dictaminadora para la Fabricación de escopetas en gran escala, 20/08/1918, AME. Sign. B 53.

94 Denominación que Orbea y Cía. adoptó durante aquellos años.

95 Acta de la reunión de, José Ramón Iriondo (Alcalde), Julián Echeverría, fabricantes de armas y las denominadas fuerzas vivas de Eibar para tratar el asunto de la fábrica de escopetas, 09/08/1918, AME Sign. B 53.
} 
CUADRO 4

DISTRIBUCIÓN DE LOS CAPITALES SUSCRITOS PARA EL PROYECTO DE FÁBRICA

DE ESCOPETAS EN EIBAR

\begin{tabular}{lcccr}
\hline \multicolumn{1}{c}{ Grupo } & N. ${ }^{\circ}$ suscriptores & $\begin{array}{c}\text { Capital medio } \\
\text { por suscriptor }\end{array}$ & Capital suscrito & $\%$ \\
\hline Propietarios & 15 & 1.260 & 18.900 Pts & 12,1 \\
Comerciantes & 15 & 713 & 10.700 Pts & 6,9 \\
Clase Media & 25 & 676 & 16.900 Pts & 10,8 \\
Obreros & 69 & 254 & 17.500 Pts & 11,2 \\
Fabricantes e industriales & 49 & 1.880 & 92.100 Pts & 59,0 \\
\hline Total & $\mathbf{1 7 3}$ & $\mathbf{9 0 2}$ & $\mathbf{1 5 6 . 1 0 0}$ & $\mathbf{1 0 0 , 0}$ \\
\hline
\end{tabular}

Fuente: Archivo Municipal de Eibar. Sign. B. 53.

\subsubsection{El Banco Oficial de Pruebas}

Una de las instituciones asociadas a los distritos industriales dedicados a la fabricación de armas es el Banco de Pruebas. Piore y Sabel ${ }^{96}$ citan expresamente, además de las instituciones de formación profesional, el caso del banc d'epreuve de Saint Etienne como ejemplo de institución característica del distrito industrial ${ }^{97}$.

La función del Banco de Pruebas era ejercer el control de calidad de las armas fabricadas para lo que éstas eran sometidas a una serie de pruebas de resistencia y tiro. En Eibar había existido ya desde el siglo XIX un Banco de Pruebas de Cañones, pero éste, al contrario que en otros países, carecía de oficialidad y, por tanto, la prueba no era obligatoria. Esta situación facilitó el que muchos industriales utilizaran la reducción de la calidad como estrategia para abaratar costes y poder competir así en los mercados exteriores ${ }^{98}$. No eran pocas las voces que solicitaban el establecimiento en España de la prueba obligatoria para, de esta forma, conseguir definitivamente acabar con la imagen negativa que las armas eibarresas habían adquirido en los mercados. La mayor parte de estas opiniones procedían principalmente de las Sociedades Obreras y de sus representantes en el Ayuntamiento, pero también había

\footnotetext{
$96 \quad$ Piore y Sabel (1990), p. 51.

$97 \quad$ Lieja y Birmingham también contaban con establecimientos de este tipo.

98 "El centro armero español extiende de día en día sus relaciones con Francia. La falta de prueba obligatoria da a los fabricantes españoles una sensible ventaja, bajo el punto de vista de precios para la venta y la causa de la seguridad no importa siempre a los compradores extranjeros y consideran que son los precios de Eibar los que les importan." Sarasqueta (1907). Ver también Goñi (2008), pp. 208-214.
} 
quien se oponía a la implantación de esa institución por considerarla contraria a la libertad de industria ${ }^{99}$ :

“Hizo uso de la palabra el Sr. Alcalde y explicó con detalles los grandes inconvenientes que ofrecería el establecimiento de tal Banco o prueba obligatoria pues ello sería la protección más grande que este pueblo podría conceder a Bélgica tanto en el orden económico como en el industrial y que si se implantara en la forma que se pretende en el escrito de la Sociedad de Pistoleros sufriría Eibar las consecuencias que serían grandes y difíciles de remediar. Añade el Sr. Alcalde que para evitar las imperfecciones de que hacen mérito la única solución factible sería el que los obreros que observan lo que alegan tengan más escrupulosidad en sus trabajos y estén los talleres sometidos a la disciplina natural que requieren y el patrono haga el reconocimiento que crea necesario pues de esta manera el buen género será asociado por los mercados, así como el defectuoso llevará el castigo que se merece, pues el comercio es el mejor jurado para apreciar los méritos de cada industria y por tanto todo lo que se haga en otro orden de cosas sería un atentado a la libertad industrial a la que no se sometería nadie" ${ }^{100}$.

Estas reticencias hicieron que el proyecto no se hiciera efectivo hasta algunos años más tarde cuando, tras intensas negociaciones, se consiguió que el Gobierno aprobara mediante R.O. de 31 de enero de 1915 la ley que regulaba la instalación de Bancos de Pruebas para armas. Pero, la imposibilidad de establecer los necesarios acuerdos internacionales para el reconocimiento mutuo de los punzones de prueba mientras durara la Primera Guerra Mundial, junto a la escasez de municiones generada por ella, hacía inviable la puesta en funcionamiento de la institución, por lo que, por R.O. de 30 de diciembre de 1916 la ley quedó en suspenso ${ }^{101}$. Una vez terminado el conflicto, y salvadas esas dificultades, el Banco de Pruebas comenzó a funcionar en $1923^{102}$. La ley establecía que estos establecimientos debían ser financiados por los propios fabricantes mediante un sistema acordado entre ellos y el Ministerio de la Guerra, pues su dirección estaría a cargo de funcionarios militares. En el caso de Eibar se estableció una tasa por arma probada para

99 Estos conflictos entre los obreros especializados y los empresarios por la calidad de los productos fueron comunes en otros distritos industriales de origen tradicional al iniciarse el proceso de liberalización de la actividad, presionando a los artesanos para que bajaran sus precios incitándoles a competir entre ellos. En la mayoría de los casos estas tensiones se solucionaban mediante el establecimiento de precios mínimos por el trabajo de los artesanos. Ver Poni (1997), pp. 60-61 y Cottereau (1997), pp. 123-131 para el caso del distrito sedero Lyon y Boch (1997), pp. 166-168 para el caso del distrito cuchillero de Solingen.

100 Acta de la sesión del pleno del Ayuntamiento de Eibar, 07/09/1905, AME. Sign. A11.20.

101 El Banco de Pruebas marca las armas con una inscripción que certifica la superación de la prueba, el reconocimiento mutuo de las inscripciones de los Bancos de Prueba evitaba que el arma debiera ser probada de nuevo al ser importada en otro país con prueba obligatoria.

Goñi (2007), p. 404. 
poder obtener los recursos necesarios para sufragar los gastos de la institución y su personal.

\section{Conclusiones}

Como hemos visto a lo largo del presente artículo, en el caso de Eibar se cumplen muchas de las características asignadas a un distrito industrial marshalliano clásico. Algunas de ellas tenían su origen en el sistema gremial que había regido la industria armera durante el Antiguo Régimen, pero otras fueron surgiendo como respuesta a los cambios provocados por la liberalización de la producción de armas y la integración en el mercado mundial. Sin duda el mayor grado de madurez del distrito industrial de Eibar se alcanzó tras la Primera Guerra Mundial cuando instituciones como la Escuela de Armería o el Banco Oficial de Pruebas lograron materializarse definitivamente.

A lo largo de este artículo ha quedado demostrado que la industria armera se configuró como una red de empresas especializadas en distintas fases de la producción, desde los pequeños talleres fabricantes de piezas hasta las empresas montadoras que, ejerciendo el papel de empresarios puros propuesto por Becattini, realizaban la labor de intermediación entre las dinámicas internas del distrito y el mercado mundial al que iban destinados la mayor parte de sus productos.

En el distrito industrial de Eibar se fabricaban distintas variedades de un producto relativamente homogéneo, aunque existían ciertas diferencias tanto en la organización de la producción como en las características del mercado en función del tipo de arma. Así, la dependencia de las armas largas de caza con respecto al mercado interior era superior, además de exigir una mayor capacitación profesional de su personal. Como consecuencia de ello, el tamaño medio de las empresas dedicadas a ese producto era relativamente pequeño y, al igual que en Lieja, Birmingham o Saint Etienne, la presencia del trabajo a domicilio era mucho más intensa que en el caso de las armas cortas. En estas últimas, la cualificación técnica de los obreros tenían una relevancia menor en el proceso productivo y la tendencia a la producción en serie era mucho más acusada. Pero, al contrario de Lieja donde existía la Fabrique National d'Armes de Guerre (FN) o Saint Etienne con su Manufacture d'Armes et Cycles, en Eibar no hubo una gran empresa dedicada a la producción en masa de armas cortas. La estructura organizativa de la producción, a pesar de una mayor dimensión media de los talleres, se rigió por características similares a la de las armas largas. También en este caso, existían multitud de empresas de fase aunque un menor recurso al trabajo a domicilio. Esta estructura permitió a estas empresas adaptarse fácilmente a las variaciones de la demanda y a los gustos del consumidor, lo que, unido a la mayor integración de los mercados 
internacionales, se tradujo en una importante expansión de la producción a finales del siglo XIX y principios del XX.

Hemos podido ver el papel jugado por las normas internas del distrito en la regulación del mercado de trabajo y, teniendo en cuenta que la mayor parte de la producción se hacía a destajo, también de los precios de los productos intermedios. Esta regulación se materializó primero, tras la liberalización de esta industria, mediante el concurso de las asociaciones de oficio herederas de los gremios armeros y posteriormente, a medida que la armas cortas fueron mayoritarias en la producción armera eibarresa, a través del Sindicato de Obreros Pistoleros. Como vimos, la actividad de esta asociación trascendió incluso el ámbito territorial de la zona armera.

En cuanto a los empresarios, se ven cumplidos muchos de los presupuestos de Marshall, Becattini o Piore y Sabel. En los comienzos del desarrollo de la industria moderna en el distrito industrial de Eibar predominaba el empresario hecho a sí mismo quien, influido por la atmósfera industrial exportadora reinante en la localidad y a pesar de su escasa formación, era capaz de aventurarse en mercados tan lejanos como extraños para la mayor parte de los industriales españoles. La existencia de estos empresarios surgidos desde abajo hacía que muchos de ellos se relacionaran con familiaridad con sus empleados y que, a simple vista, fuera difícil distinguir a unos de otros o que se diera, también, la aparente contradicción de que algunos de los líderes socialistas más influyentes y beligerantes de la localidad fueran, al mismo tiempo, miembros de la patronal. Por otra parte hemos visto que, aun en lo más enconado de una huelga, la conflictividad laboral nunca se saldó con hechos violentos de relevancia, a pesar de la gran cantidad de armas disponible.

Otro de los aspectos destacables del caso de Eibar fue la creación de instituciones comunes en beneficio del conjunto del distrito como la Escuela de Armería o el Banco de Pruebas, en cuya promoción, la actuación del Ayuntamiento resultó fundamental tanto a la hora de afrontar las negociaciones con la administración central como en el aunamiento de voluntades en favor de esas iniciativas.

La mayor debilidad de Eibar como ejemplo de distrito industrial radica en el aspecto de la cooperación entre las empresas ${ }^{103}$. Sí que se han detectado algunos intentos de colaboración para llevar a cabo proyectos en común como, por ejemplo, la creación de la Fundición Aurrera, empresa financiada por varios industriales armeros de la localidad para asegurarse el suministro de hierros maleables en condiciones favorables. Durante la Primera Guerra Mundial hubo, también, varias tentativas para establecer tarifas comunes, tratando de evitar que la competencia interna malo-

103 Tampoco se ha detectado hasta el momento la existencia de una entidad de crédito local como la propuesta por Becattini. 
grara el gran negocio que suponía la venta de armas a los contendientes ${ }^{104} \mathrm{y}$, finalmente, en la crisis de los años 20, la mayoría de los fabricantes de revólveres se sindicaron para evitar así la bajada de precios provocada por la presión de las empresas comercializadoras ${ }^{105}$. Entre éstas quizá la más relevante sea la creación de la Cámara Oficial Armera por Real Orden de 14 de julio de 1927, institución a la que se atribuían funciones de representación, regulación de ventas y precios, así como de fomento del sector, facultándosele también para la adopción de medidas que favorecieran la reconversión hacia otras ramas de actividad ${ }^{106}$. La información disponible hasta el momento no nos permite evaluar adecuadamente la importancia y el nivel de éxito obtenido por estos ejemplos de cooperación, sin embargo, son más frecuentes las referencias a los fracasos que a los éxitos de este tipo de iniciativas, respondiendo muchas de ellas no tanto a intereses del conjunto del distrito sino a los de un grupo limitado de empresarios. En los textos contemporáneos se cita recurrentemente el inveterado individualismo de los armeros eibarreses, o a su carácter despilfarrador, que hacían fracasar muchas de las iniciativas del distrito ${ }^{107}$, y en la documentación municipal no es raro toparse con las quejas del alcalde de turno por la escasa asistencia de productores a las reuniones convocadas por el Ayuntamiento para tratar asuntos relacionados con la armería. No olvidemos, por ejemplo, la actitud que algunos concejales-armeros del Ayuntamiento mantuvieron ante la instauración de la prueba obligatoria, la financiación de la Escuela de Armería o las razones por las que J. Esperanza y P. Unceta decidieron trasladarse fuera de Eibar. Aunque, sin duda, el fracaso más notorio de este tipo de iniciativas fue el proyecto de fabricación en serie de escopetas propuesto por el profesorado de la Escuela de Armería que pretendía, como hemos visto, no sólo superar la esperada crisis tras la finalización de la Primera Guerra Mundial sino, también, reducir la dependencia de la industria eibarresa con respecto a las armas cortas.

Valdaliso y López señalan que el fracaso de muchos de estos distritos industriales en su lucha contra la producción en masa fue consecuencia de la sustitución de la cooperación entre los agentes del distrito por la competencia. También asocian estas dificultades a la adopción de la reducción de la calidad, los precios o los salarios como vía para el incremento de la competitividad ${ }^{108}$. A pesar de que en Eibar existieran resistencias a la cooperación y claras tendencias a la reducción de precios y calidades, los mecanismos internos de regulación del distrito consiguieron atem-

\footnotetext{
104 Sarasketa (1907), también nos cita intentos anteriores de acuerdos de este tipo.

105 Iza-goñola (2005), pp. 24-25.

106 Gaceta de Madrid n. ${ }^{\circ}$ 196, 15 de julio de 1927, pp. 282-285.

107 "Se ha achacado a los eibarreses que, por efecto de su carácter alegre y bullicioso, y por la afición a las francachelas, disipan todas sus ganancias...", Discurso pronunciado por el Excmo. Señor don Pablo de Alzola en la velada celebrada en Eibar la noche del 5 de septiembre de 1908 en Mujica (1908), pp. 493-496.

Valdaliso y López (2000), p. 326.
} 
perarlas en gran medida, logrando que éste mantuviera su identidad como distrito industrial.

En este trabajo hemos pretendido realizar una primera aproximación al caso de la industria armera de Eibar desde la perspectiva del distrito industrial marshalliano. La posterior evolución de la industria hacia la manufactura de otros productos como las máquinas de coser, las bicicletas o el material de oficina, que entendemos como un mecanismo del propio distrito para superar la crisis de entreguerras, cambiaron completamente la fisonomía sectorial del mismo ${ }^{109}$. Sería necesaria, pues, la realización de un estudio más amplio del caso de Eibar yendo más allá de los límites que impone el tradicional enfoque sectorial, para poder analizar si, a pesar de esos cambios, Eibar siguió manteniendo su esencia como distrito industrial aun cuando la industria armera había comenzado ya a experimentar cierto declive. Este trabajo se ha limitado también, desde un punto de vista geográfico, al principal núcleo urbano de la zona armera donde se concentraba la mayor parte de esta actividad y se manifestaron buena parte de las características de los distritos industriales clásicos. Pero, quizá fuera necesario abordar este análisis desde un enfoque territorial más amplio estudiando los vínculos entre los distintos municipios de la zona para poder determinar así el grado de interrelación entre la industria armera y el desarrollo de otras actividades como, por ejemplo, la producción de máquina herramienta, con una importante presencia en la vecina localidad del Elgoibar y a la que también se dedicaron muchas empresas armeras eibarresas tras la guerra civil ${ }^{110}$.

\section{Fuentes}

Archivo Gernikazarra (AG)

Archivo Municipal de Eibar (AME)

\section{Bibliografía}

ALDABALDETRECU, Patxi (2000): Máquinas y Hombres. Guía histórica, Elgoibar, Fundación Museo de Máquina-Herramienta.

\footnotetext{
109 Goñi (2007), pp. 420-421. La evolución de los distritos industriales hacia la poli-especialización es considerada por algunos autores como una estrategia de adaptación ante cambios externos. Ruiz Fuensanta (2008).

$110 \quad$ Aldabaldetrecu (2000).
} 
ANTARIS, Leonardo M. (1988): Astra Automatic Pistols, Colorado, Firac Publishing Co., Sterling.

-(2001): Star Firearms, Davenport, Firac Publishing Co.

ASTRA UNCETA Y COMPAÑíA (1958): 1908-1958. ASTRA Unceta y Compañía, S.A., Historia de una empresa, Bilbao, Ed. Grijelmo.

AZPIAZU, José Antonio (2002): Picas vascas en Flandes. Historias de armas de Euskal Herria, San Sebastián, Ttarttalo argitaletxea.

BECATTINI, Giacomo (1979): «Dal «settore» industriale al «distretto» industriale. Alcune considerazioni sull'unità di indagine dell'economia industriale», en L'Industria. Rivista di economia e politica industriale, n. ${ }^{\circ} 1$, pp. 7-21.

-(1990): "El distrito industrial marshhaliano como concepto socioeconómico" en Los distritos industriales y las pequeñas empresas. I. Distritos industriales y cooperación interempresarial en Italia en PYKE, BECATTINI Y SENGENBERGER (comp.), Ministerio de Trabajo y Seguridad Social, Madrid, pp. 61-79.

-(2005): La oruga y la mariposa. Un caso ejemplar de desarrollo en la Italia de los distritos industriales. Prato (1954-1993), Valladolid, Universidad de Valladolid.

-(2006): "Vicisitudes y Potencialidades de un concepto: el distrito industrial" en El distrito industrial Marshalliano. Un balance crítico de 25 años, Economía Industrial, n. ${ }^{\circ}$ 39, Madrid, Ministerio de Industria Turismo y Comercio, pp. 21-28.

BOCH, Rudolf (1997): "The rise and decline of flexible production: cutlery industry of Solingen since the eighteenth century" en SABEL, Charles F. and ZEITLIN, Jonathan (eds.), World of possibilities. Flexibility and mass production in western industrialization, Cambridge University Press, Cambridge, pp. 153-187.

BUDÍ, Vicente (2008): “El distrito de la cerámica de Castellón” en Mediterráneo Económico. Fundación Cajamar, Colección de Estudios Socioeconómicos, n. ${ }^{\circ} 13$. Los distritos Industriales, pp. 383-408.

CABALLER VIVES, María Cinta (2000): “La influencia de las Escuelas de Armería de Liége y Saint Etienne en la creación y posterior desarrollo de la Escuela de Armería de Eibar" en Proceedings of the XXth International Congress of History of Science (Liége 20-26, July 1997), Ed. Brepols, Turnhout, Vol. VII. Technology and engineering, pp. 291-307.

CALVÓ, Juan L. y JIMÉNEZ SANCHEZ-MALO E. (1993): 1840-1940 Cien años de pistolas y revólveres españoles, Pontevedra, Asociación Española de Coleccionistas de Armas Antigüas y Recuerdos Históricos “CID”.

CALVÓ, Juan L. (1997): La Industria Armera Nacional 1830-1940. Fábricas, Privilegios, Patentes y Marcas, Eibar, Comisión Ego Ibarra.

CARRIÓN, Ignacio (2000): "Sixteenth and Seventeenth Century Arms Production in Gipuzkoa" en Proceedings of the XXth International Congress of History of Science (Liége 20-26 July 1997), Vol. VII. Technology and Engineering, Ed. Brepols, Turnhout, pp. 265-279. 
CATALÁN, Jordi (1990): “Capitales modestos y dinamismo industrial: Orígenes del sistema de fábrica en los valles guipuzcoanos, 1841-1918" en Pautas regionales de la industrialización española (siglos XIX y XX), Barcelona, Ariel, pp. 125-158.

COTTEREAU, Alain (1997): "The fate of collective manufacturers in the industrial world: the silo industries of Lyons and London, 1800-1850", en SABEL, Charles F. y ZEITLIN, Jonathan (eds.), World of possibilities. Flexibility and mass production in western industrialization, Cambridge, Cambridge University Press, pp. 75-152.

ECHEVARRIA, Toribio (1990): Viaje por el País de los Recuerdos, San Sebastián, Sociedad Guipuzcoana de Ediciones y Publicaciones.

EGUREN, José María (1923): Breve Historial del Pleito Armero, Eibar.

ETXANIZ, José Ángel (2000): “Gernika-Lumo, 1913, Industrialización, movimiento obrero y conflicto social: la huelga de "Esperanza y Unceta" en Vasconia, Cuadernos de historia-geografía, n. ${ }^{\circ}$ 30, pp. 141-162.

FERNÁNDEZ DE PINEDO, Emiliano (2005): prólogo a ALFA, S.A. Motor social y económico de la vida eibarresa, Comisión Ego Ibarra, Ayuntamiento de Eibar, Eibar.

GAIER, Claude (1996) : Cinq siècles d'armurerie liégeoise, Alleur, Editions du Perron.

GOÑI MENDIZABAL, Igor (2007): “Evolución de la industria armera vasca (18761969): Un enfoque a largo plazo" en PASCUAL, Pere y FERNÁNDEZ PÉREZ, Paloma (eds.), Del metal al motor. Innovación y atraso en la historia de la industria metal-mecánica española, Barcelona, Fundación BBVA, pp. 385-432.

-(2008): “Imitación, innovación y apoyo institucional. Estrategias de penetración en los mercados internacionales de las empresas armeras vascas durante el siglo XX", Revista de la Historia de la Economía y de la Empresa, n. ${ }^{\circ}$ 2, pp. 207-236.

-(2009a): “De Esperanza y Unceta a Astra-Unceta y Cía., una empresa armera ante el mercado internacional", Revista de Historia Industrial, n. ${ }^{\circ} 40$, pp. 40-51.

-(2009b): “La internacionalización de la industria armera vasca, 1876-1970. El distrito industrial de Eibar y sus empresas.", Información Comercial Española Revista de Economía, n. ${ }^{\circ} 849$, pp. 79-96.

IZA-GOÑOLA, Francisco Javier (2005): ALFA, S.A. Motor social y económico de la vida eibarresa, Comisión Ego Ibarra, Eibar, Ayuntamiento de Eibar.

LARRAÑAGA, Ramiro (1981): Síntesis Histórica de la Armería Vasca, San Sebastián, Caja de Ahorros Provincial de Guipúzcoa.

-(2001): Armeros Vascos, Repaso Histórico- Raíces y Desarrollo, Eibar, Ego Ibarra.

MAGNUSSON, Lars (1994): The Contest for Control. Metal industries in Sheffield, Solingen, Remscheid and Eskiltsuna during Industrialization, Oxford, Berg.

MARSHALL, Alfred y MARSHALL, Mary Paley (1879): The Economics of Industry, Londres, McMillan.

MARSHALL, Alfred (1954): Principios de Economía, Madrid, Ed. Aguilar. 
MIRANDA, José Antonio (2005): “Calzado y Distritos Industriales en el Mediterráneo: una visión de largo plazo", en Mediterráneo Económico. Colección de Estudios Socioeconómicos, n. ${ }^{\circ}$, Mediterráneo e Historia Económica, pp. 289-312.

MONTERO, Manuel (2006): Las Cortes del Desastre «Impresiones Parlamentarias» Publicadas en El Liberal, de Bilbao, por Indalecio Prieto, Bilbao, Universidad del País Vasco-Euskal Herriko Unibertsitatea.

MUJICA, Gregorio de (1908): Monografía histórica de la Villa de Eibar, $3^{\text {a }}$ edición, Eibar, 1984, Ayuntamiento de Eibar.

PAUL ARZAC, Juan Ignacio (1976): Evolución de la industria armera de Eibar, San Sebastián, Cámara de Comercio, Industria y Navegación de Guipúzcoa.

PIORE, Michael y SABEL, Charles (1990): La segunda ruptura industrial, Madrid, Alianza Universidad.

PONI, Carlo (1997): "Fashion as flexible production: the strategies of the Lyons silk merchants in the eighteenth Century" en SABEL, Charles F. Y ZEITLIN, Jonathan (eds.), World of possibilities. Flexibility and mass production in western industrialization, Cambridge, Cambridge University Press.

RUIZ FUENSANTA, María Jesús (2008): “La poliespecialización como fuente de dinamismo del distrito industrial", en Mediterráneo Económico. Colección de Estudios Socioeconómicos, n. ${ }^{\circ}$ 13, Los distritos Industriales, pp. 139-157.

SARASKETA, Pedro de (1907): “La Industria armera en Eibar juzgada por la prensa extranjera de un pueblo rival: un artículo importante en Euskal-Erria Revista Vascongada", T. 57 (2 sem. 1907), pp. 481-485.

SCRANTON, Philip (1997): Endless novelty. Specialty production and American Industrialization, 1865-1925, Princeton, Princeton University Press.

TRULLÉN, Joan (2006): "El análisis de los procesos industriales en clave de "distrito"'" en El distrito industrial Marshalliano. Un balance crítico de 25 años, Economía Industrial, n. ${ }^{\circ}$ 39, Madrid, Ministerio de Industria Turismo y Comercio, pp. 17-20.

URDANGARÍN, Carmelo; IZAGA José María y LIZARRALDE, Koldo (1994): Antzinako Lanbideak-Oficios Tradicionales, San Sebastián, Cámara de Gipuzkoa.

VALDALISO Jesús María y LOPEZ, Santiago (2000): Historia Económica de la Empresa, Barcelona, Crítica.

VICTOR SARASQUETA, CORTABERRÍA Y CÍA (1904): Manufacturera mecánica eibarresa, Fabricación de armas finas de caza, Victor Sarasqueta, Cortaberría y Cía, Catálogo, Eibar.

ZEITLIN, Jonathan (2007): “Industrial districts and regional clusters" en JONES, Jeffrey y ZEITLIN, Jonathan (eds.), The Oxford Handbook of Business History, Oxford University Press, Oxford, Cap. 10. 